\title{
Nalfurafine hydrochloride to treat pruritus: a review
}

This article was published in the following Dove Press journal:

Clinical, Cosmetic and Investigational Dermatology

II May 2015

Number of times this article has been viewed

\author{
Shigeki Inui \\ Department of Regenerative \\ Dermatology, Osaka University \\ Graduate School of Medicine, \\ Osaka, Japan
}

Correspondence: Shigeki Inui Department of Regenerative Dermatology, Osaka University Graduate School of Medicine, 2-2, G2, Yamadaoka, Suita-shi, Osaka 565087I, Japan

Tel +8I 668793960

Email inui@r-derma.med.osaka-u.ac.jp
Abstract: Uremic pruritus has a great negative influence on quality of life in hemodialysis (HD) patients and, importantly, negatively affects mortality risk. Recently, nalfurafine hydrochloride, an opioid $\kappa$-selective agonist, has been officially approved for resistant pruritus in HD patients on the basis of a well-evidenced clinical trial in Japan. From clinical observation, it has been suggested that the upper neuron system plays a role in its pathogenesis. According to previous experimental results, using mice injected with opioids, dynorphin suppresses itch through binding $\kappa$-opioid receptors, suggesting that $\kappa$-opioid opioid receptor agonists act as potential therapeutic reagents for pruritus in HD patients. In Japan, a large-scale placebo-controlled study was performed to examine the efficacy and safety of oral nalfurafine hydrochloride for intractable pruritus in $337 \mathrm{HD}$ patients. Two daily doses of 2.5 or $5 \mu \mathrm{g}$ nalfurafine or placebo were orally administered for 2 weeks, and clinical responses were analyzed. The results showed that the mean decrease in the visual analog scale for pruritus from baseline was $22 \mathrm{~mm}$ in the $5 \mu \mathrm{g}$ nalfurafine hydrochloride group $(\mathrm{n}=114)$ and $23 \mathrm{~mm}$ in the $2.5 \mu \mathrm{g}$ group $(\mathrm{n}=112)$. These reductions were statistically significant compared with $13 \mathrm{~mm}$, which is the mean decrease of visual analog scale in the placebo group $(n=111)$, demonstrating that nalfurafine is an effective and safe drug for uremic pruritus in HD patients. Moreover, another open-label trial $(n=145)$ examining the long-term effect of $5 \mu \mathrm{g}$ oral nalfurafine revealed the maintenance of the antipruritic effect of nalfurafine for 52 weeks. In addition, on the basis of recent data showing $\kappa$-opioid receptor expression in the epidermis of atopic dermatitis and psoriasis, nalfurafine hydrochloride also can be potentially used for these two skin diseases.

Keywords: nalfurafine hydrochloride, uremic pruritus, opioid $\kappa$-selective agonist, hemodialysis

\section{Introduction}

The hemodialysis (HD) patient population in Japan has been growing every year, and a Japanese nationwide statistical survey of 4,238 dialysis facilities indicated that the number of new dialysis patients was 38,055 in 2012, and the number of dialysis patients per million was $2,431.2{ }^{1}$ Although HD negatively affects the quality of life (QOL) of the patients, uremic pruritus in particular has a great negative influence on their QOL. The Dialysis Outcomes and Practice Patterns Study (1996-2004) collected the previous data from 18,801 HD patients and showed that moderate to extreme pruritus was experienced by $42 \%$ of the patients. Further, pruritus was associated with feeling drained, poor sleep quality and QOL, depression, and importantly, a higher mortality risk. ${ }^{2}$ Similar results were obtained in a Japanese report assessing 1,773 HD patients. ${ }^{3}$ Therefore, treatment for pruritus in HD patients was very important for 
not only their QOL but also their prognosis. Unfortunately, pruritus is often resistant to treatment with various conventional drugs. Indeed, various treatments such as gabapentin, ${ }^{4}$ capsaicin cream, ${ }^{5,6}$ ultraviolet B therapy, ${ }^{7}$ thalidomide, ${ }^{8}$ endocannabinoid cream, ${ }^{9}$ and tacrolimus ointment ${ }^{10,11}$ were used in clinical practice, and in some cases, these options were found to be effective. However, there were no drugs satisfactorily effective for severe HD-related pruritus. As for the clinical studies, even if preferential results for some drugs were reported once, they were followed by studies with contradictory results. ${ }^{12-15}$ Collectively, uremic pruritus is still a very difficult target to treat, and new effective treatments are expected to be developed.

Recently, nalfurafine hydrochloride has been officially approved for resistant pruritus in HD patients on the basis of a well-evidenced clinical trial in Japan. ${ }^{16}$ In this review, uremic pruritus in HD patients, its pathophysiology, and this new drug are reviewed. In addition, potentials of nalfurafine hydrochloride as a therapeutic reagent for other pruritic skin diseases are discussed.

\section{HD-induced pruritus and its pathophysiology}

Cutaneous manifestations in HD patients are divided into two groups: specific and nonspecific abnormalities. The former includes pruritus, xerosis, hyperpigmentation or hypopigmentation, and acquired ichthyosis. Nonspecific abnormalities include acquired perforating disease (Figure 1), calciphylaxis, bullous dermatosis, and fibrosing dermopathy of uremia. ${ }^{17}$ Among these complications, most conditions are associated with pruritus. Pruritus also occurs in patients with

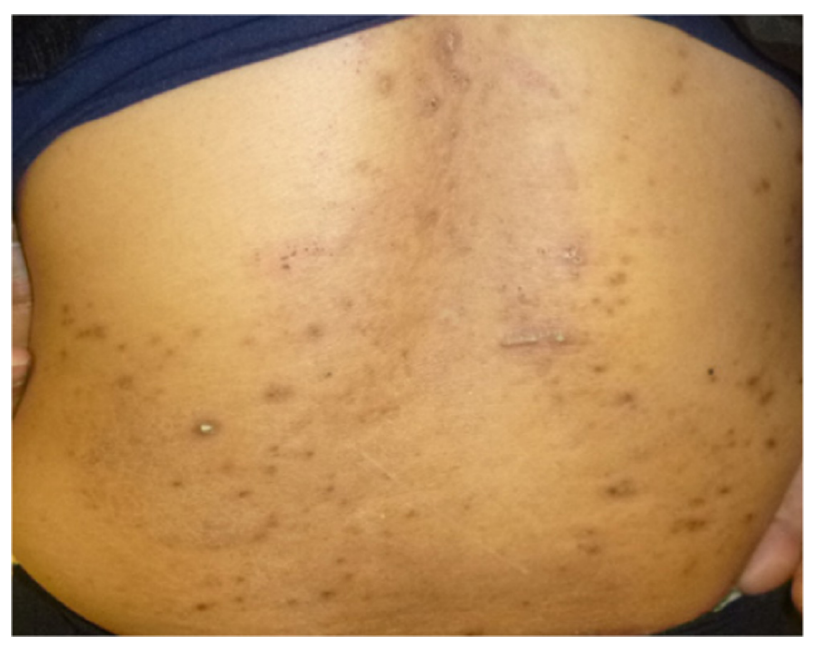

Figure I Clinical appearance of acquired perforating disease in a 58-year-old Japanese woman receiving hemodialysis. end-stage renal disease and is referred to as uremic pruritus or chronic kidney disease-associated pruritus. ${ }^{18}$ This symptom lasts for months to years in most cases and is resistant to conventional treatments. ${ }^{19}$ As mentioned earlier, pruritus has great influence on the patients' QOL and prognosis.

One reason for the difficulty in the development of effective therapeutic reagents for uremic pruritus is that its pathophysiology is still not fully uncovered. Until now, various substances have been investigated as possible pathogenetic factors in pruritus associated with chronic renal disease. For example, according to previous case reports, persistent uremic pruritus of patients with secondary hyperparathyroidism decreased after parathyroidectomy; ${ }^{20,21}$ therefore, parathormone was speculated to be a potential pruritogen. Nevertheless, intradermal application of parathormone did not cause a significant skin reaction in humans, and further, this hormone could not be detected in uremic pruritus patients, ${ }^{22}$ indicating that the likelihood of parathormone as a pruritogen is low. In addition, further clinical study and the development of parathormone-related reagents were not carried out.

On the basis of elevated plasma histamine in patients with uremic pruritus, ${ }^{23,24}$ histamine has been suggested to be a pathogenic substance. However, antihistamines could not suppress pruritus in HD patients, ${ }^{25}$ and therefore histamine is unlikely to be a pruritogen. In addition, tryptase, another mediator released from mast cells in the serum of patients with uremic pruritus, was elevated, ${ }^{26}$ suggesting mast cells play some role in its pathogenesis.

From the clinical finding that xerosis is often seen in HD patients, ${ }^{27}$ pathogenesis of HD-induced pruritus can be ascribed to skin barrier dysfunction. Xerosis is associated with systemic diseases such as renal failure, HD, cholestatic jaundice, and liver cirrhosis. ${ }^{28}$ Pruritus caused by these systemic diseases is resistant to antihistamines, possibly because skin barrier destruction induces an increase of neuron fibers in the epidermis. ${ }^{29}$ Indeed, neuron-specific enolase-immunoreactive nerve fibers were reported to increase in the epidermis of HD patients. ${ }^{30}$ However, moisturizers or emollients, which exert their therapeutic activity through the improvement of skin barrier function, are generally ineffective for HD-related pruritus, suggesting the upper neuron system plays a role in the condition's pathogenesis. On the basis of previous results of experiments using mice injected with opioids, itching is induced by opioids through central $\mu$-opioid receptors. ${ }^{31}$ In contrast, dynorphin suppresses itch through binding $\kappa$-opioid receptors. ${ }^{32}$ From these findings, the balance between $\mu$ - and $\kappa$-opioid opioid 
receptors can regulate pruritus, suggesting $\kappa$-opioid opioid receptor agonists as a potential therapeutic reagent for pruritus in HD patients.

\section{Nalfurafine hydrochloride as a new antipruritic drug}

A highly $\kappa$-selective agonist U-50488H was constructed in 1982 after long-term efforts toward the development of opioid $\kappa$-selective agonist without morphine-like adverse effects such as respiratory depression, constipation, and physical dependence. ${ }^{33}$ However, because U-50488H and its derivatives caused different adverse effects such as dysphoria and psychotomimetic effects, unfortunately, they could not reach clinical use. ${ }^{34}$ Later, a Japanese group succeeded in designing and developing nalfurafine hydrochloride (TRK-820) (Figure 2), a new type of nonpeptide $\kappa$-agonist with a novel chemical structure, in $1998 .{ }^{35}$ This reagent has the tyrosineglycine moiety for endogenous opioid peptides such as dynorphins. This structure was constructed on the basis of the "message-address concept." ${ }^{36,37}$ According to this notion, the 4,5-epoxymorphinan skeleton is defined as the message subside acting as opioids, and the other structural part is defined as the address subside regulating the receptor type selectivity. Nalfurafine hydrochloride is a potent and selective agonist for mouse, rat, guinea pig, and human $\kappa$-opioid receptors without significant activity on $\mu$ - and $\delta$-opioid receptors. ${ }^{35,38-40}$ This drug shows little or no suppressive effect on the secretion of potential mediators for pruritus, including histamine; cytokines such as tumor necrosis factor $\alpha$, interleukin $1 \beta$, and interleukin 6; and prostaglandins such as prostaglandin $\mathrm{E}_{2}$ or $\mathrm{D}_{2} \cdot{ }^{39,40}$ In addition, the affinities of nalfurafine hydrochloride to various kinds of receptors were examined by binding assays, and it was found that nalfurafine

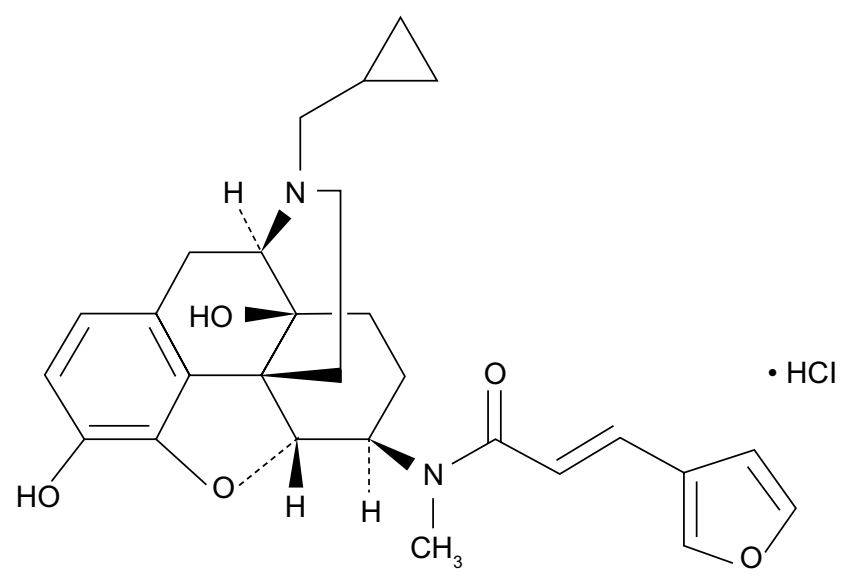

Figure 2 Chemical structure of nalfurafine hydrochloride. hydrochloride bound to the muscarinic acetylcholine $M_{1}$ receptor with very low affinity $(\mathrm{Ki}=1,700 \mathrm{nmol} / \mathrm{L})$ but did not displace radioligands from a variety of other binding sites. ${ }^{39,40}$ On the basis of animal experiments using pruritogeninduced scratching in mice, nalfurafine hydrochloride suppressed scratching behaviors, ${ }^{41}$ and this inhibitory effect was antagonized by intracerebroventricular (central) administration of norbinaltorphimine, a א-opioid receptor antagonist in mice, ${ }^{42}$ demonstrating the antipruritic effect of nalfurafine hydrochloride through central $\kappa$-opioid receptor activation. From the results of conditioned place preference procedure experiments using rats, nalfurafine at $10-40 \mu \mathrm{g} / \mathrm{kg}$ did not produce either place aversion or preference, suggesting an absence of drug aversion and addiction. ${ }^{43}$ Further, nalfurafine would constitute a new, effective, and safe reagent, so that a clinical study was undertaken.

\section{Clinical trials of nalfurafine hydrochloride for HD-induced pruritus}

According to a meta-analysis of two randomized placebocontrolled studies, it was revealed that intravenous nalfurafine three times a week significantly reduced pruritus in $144 \mathrm{HD}$ patients. In this meta-analysis, the worst itching, itching intensity, and sleep disturbances were significantly decreased in the nalfurafine group compared with in the placebo group, ${ }^{44}$ demonstrating for the first time the antipruritic activity of nalfurafine hydrochloride in humans.

In Japan, a large-scale placebo-controlled study was performed to examine the efficacy and safety of oral nalfurafine hydrochloride for intractable pruritus in 337 HD patients. ${ }^{16}$ All enrolled patients suffered from an itch resistant to antihistamines for 2 weeks, or drugs approved for the treatment of pruritus or moisturizing agents during a 1 -year period before the clinical trial. Two doses of daily 2.5 or $5 \mu \mathrm{g}$ nalfurafine or placebo were orally administered for 2 weeks, and clinical responses were analyzed. The results showed that the mean decrease in the visual analog scale (VAS) for pruritus from baseline was $22 \mathrm{~mm}$ in the $5 \mu \mathrm{g}$ nalfurafine hydrochloride group $(\mathrm{n}=114)$ and $23 \mathrm{~mm}$ in the $2.5 \mu \mathrm{g}$ group $(\mathrm{n}=112)$. These reductions were statistically significant compared with $13 \mathrm{~mm}$, which is the mean decrease of VAS in the placebo group $(n=111)$. When $50 \%$ or more reduction of VAS values was estimated as a significant response, $32.5 \%$ (37/114) patients in the $5 \mu \mathrm{g}$ nalfurafine group and $28.6 \%$ $(32 / 112)$ in the $2.5 \mu \mathrm{g}$ nalfurafine group showed a significant response. In contrast, $17.1 \%(19 / 111)$ patients in the placebo group showed a significant response. The significant response 
rate was significantly higher in the 2.5 and $5 \mu \mathrm{g}$ nalfurafine groups than the placebo.

On the basis of these data, oral nalfurafine hydrochloride ( 2.5 or $5 \mu \mathrm{g} /$ day) is effective for uremic pruritus resistant to conventional treatments in HD patients. Moreover, the same Japanese group designed another open-label trial to examine a long-term effect of $5 \mu \mathrm{g}$ oral nalfurafine for 52 weeks. ${ }^{45}$ Although $211 \mathrm{HD}$ patients with a treatment-resistant pruritus were enrolled, 145 completed the study. In the pretreatment period, the mean pruritus VAS was $75.2 \mathrm{~mm}$, significantly decreasing to $50.9 \mathrm{~mm}$ at week $2,33.6 \mathrm{~mm}$ at week 24 , and $31 \mathrm{~mm}$ at week 52, suggesting the prolonged efficiency on pruritus. However, at 4 weeks after the treatment cessation, the VAS significantly increased to $47.9 \mathrm{~mm}$.

In this study, nighttime pruritus was monitored by the Shiratori severity score (patient assessment). The mean decrease of this score was $0.97,1.55$, and 1.57 at week 2,24 and 52, respectively, indicating maintenance of the antipruritic effect of nalfurafine until week 52. In this long-term trial, adverse drug reactions occurred in 103 (48.8\%) patients, and $6.2 \%$ discontinued the treatment as a result of adverse drug reactions. The adverse reactions were as follows: insomnia (15.2\%), constipation (3.3\%), blood prolactin elevation ( $0.9 \%)$, somnolence $(1.9 \%)$, dizziness $(0.9 \%)$, pruritus $(0.9 \%)$, diarrhea $(0.9 \%)$, malaise $(0.9 \%)$, mood alteration $(0.9 \%)$, eczema $(0.5 \%)$, vomiting $(0.5 \%)$, anemia $(0.9 \%)$, and blood thyroidstimulating hormone elevation $(0.5 \%)$. There were no clinically significant alterations in the vital signs or electrocardiograph findings. In addition, the addiction liability was assessed, but none showed psychological dependence on nalfurafine. Likewise, there was no evidence for physical dependence. In this line, another international multicenter study examined the possibility of abuse liability of nalfurafine in $146 \mathrm{HD}$ patients. ${ }^{46}$ In this clinical trial, $5 \mu \mathrm{g}$ nalfurafine was administrated intravenously for up to 52 weeks. The questionnaires of the Addiction Research Centre Inventory and modified Short Opiate Withdrawal Scale were administered to the $146 \mathrm{HD}$ patients and 81 end-stage renal disease patients without pruritus as controls. Then, there was no significant difference between the two groups in the Addiction Research Centre Inventory and modified Short Opiate Withdrawal Scale, indicating no evidence of abuse liability. Because uremic pruritus is reportedly a risk factor for depression in HD patients, ${ }^{47}$ we examined the effect of oral nalfurafine hydrochloride on pruritus and anxiety in HD patients. Then we found that nalfurafine hydrochloride significantly reduced the VAS for pruritus and state-trait anxiety inventory (STAI)1 (state anxiety), but not STAI2 (trait anxiety), suggesting the efficacy of nalfurafine hydrochloride on not only pruritus but also mental condition in HD patients..$^{48}$ Trait anxiety is characterized by a longer history, and therefore can be expected to show resistance to the treatment for only 4 weeks. Furthermore, as no psychiatric drugs were administered to the patients, and nalfurafine itself has no antianxiety effect, the effect of nalfurafine on anxiety is likely to be through itch relief. This notion is supported by previous reports showing that pruritus correlates with anxiety in connection with other skin diseases such as atopic dermatitis, ${ }^{49}$ psoriasis, ${ }^{50}$ and skin burn. ${ }^{51}$ Means of STAI1 and two scores of healthy volunteers older than 45 years $(n=805)$ were $35.54 \pm 8.920$ and $37.74 \pm 10.03$, respectively. ${ }^{52}$ A comparison of the scores of our patients before treatment with the scores of these controls shows that both STAI1 and STAI2 were significantly higher in the patients, thus demonstrating both high state and high trait anxiety in our HD patients.

\section{Pharmacokinetics}

As for pharmacokinetics, after a single administration of $2.5 \mu \mathrm{g}$ of nalfurafine hydrochloride to HD patients, $T_{\max }$ was 4.25 hours, $C_{\max } 3.15 \mathrm{pg} / \mathrm{mL}$, and $t_{1 / 2} 14.21$ hours. In the case of administration with $5 \mu \mathrm{g} /$ day of nalfurafine, $T_{\max }$ was 3 hours, $C_{\max } 6.51 \mathrm{pg} / \mathrm{mL}$, and $t_{1 / 2} 14.03$ hours. Furthermore, after repeated administration of $2.5 \mu \mathrm{g} /$ day for 12 days, $T_{\max }$ was 4.14 hours, $C_{\max } 5.70 \mathrm{pg} / \mathrm{mL}$, and $t_{1 / 2} 25.33$ hours. When $5 \mu \mathrm{g} /$ day nalfurafine was administered in the same manner, $T_{\max }$ was 3.86 hours, $C_{\max } 10.25 \mathrm{pg} / \mathrm{mL}$, and $t_{1 / 2} 28.34$ hours. ${ }^{32}$ From these findings, $C_{\max }$, area under the curve, and $t_{1 / 2}$ increase more after repeated administration than after a single administration. The decyclopropylmethylation of nalfurafine is catalyzed by CYP3A4, CYP2C8, and CYP2C19, with CYP3A4 functioning as the major metabolic enzyme. Eventually, this reagent and its metabolites are eliminated through the dialysis membrane used for HD. The plasma level of this drug was below the detection limitation 1 week after the study completion, indicating there was no systemic accumulation of nalfurafine. Collectively, nalfurafine is effective for HD-related pruritus and safe in terms of addiction and abuse liability.

\section{Potential of nalfurafine hydrochloride for the treatment of other skin diseases}

As mentioned earlier, $\mu$ - and $\kappa$-opioid receptors are key players in regulating pruritus in the central nervous system, but epidermal keratinocytes reportedly express these opioid receptors both in vitro and in vivo, ${ }^{53}$ suggesting nalfurafine can exert its antipruritic activity through $\mathrm{K}$-opioid receptors 
in the epidermis. This possibility is significant because many skin diseases with pruritus involve epidermal changes, such as spongiosis, hyperkeratosis, and acanthosis. The prototype of such cutaneous diseases is atopic dermatitis, which causes severe itch and, subsequently, scratching, exacerbating inflammation. For treatment for atopic dermatitis, it is very important to suppress itch to prevent such exacerbation. In clinical practice, antihistamines are widely used for this purpose, but in some cases, they are not effective enough to control pruritus. Therefore, a new potential antipruritic drug is expected. Along these lines, the expression of only $\kappa$-opioid receptors, not $\mu$-opioid receptors, was downregulated in the epidermis of atopic dermatitis patients compared with in normal healthy controls. ${ }^{53}$ In addition, after the improvement of dermatitis by psoralen-ultraviolet A therapy, the expression of $\kappa$-opioid receptors was restored in the epidermis. From these findings, the intraepidermal $\kappa$-opioid system plays a pivotal role in controlling peripheral itch in atopic dermatitis. Moreover, according to an animal experiment using Japanese mice (Traf3ip2/Act 1-deficient mice), nalfurafine suppresses scratching behavior in the mice. ${ }^{54} \mathrm{Col}-$ lectively, nalfurafine may be a very hopeful drug for pruritus in atopic dermatitis.

Classically, psoriasis was defined as a nonpruritic skin disease, but recently, accumulating evidence has revealed that a high percentage of psoriasis patients also suffer from pruritus, and subsequently, their QOL is greatly affected by itch. ${ }^{55-58}$ Using the structured Yosipovitch itch questionnaire, among 230 patients who returned a complete and detailed questionnaire, pruritus was referred to by $80 \%$ of the patients. In addition, the psoriasis area and severity index was significantly higher in patients with pruritus. ${ }^{55}$ The study of patients with moderate-to-severe plaque psoriasis showed that $96 \%$ of patients feel some itching, and among them, $62 \%$ reported severe itching. Further, the Dermatology Life Quality Index, Hospital Anxiety and Depression Screening Anxiety, Functional Assessment of Chronic Illness TherapyFatigue, Euro-Qol-5D VAS, and Medical Outcomes Study Sleep Index II significantly correlate with pruritus, indicating alteration of QOL in psoriasis patients by pruritus. In the epidermis of psoriasis patients with pruritus, the expression of $\kappa$-opioid receptor and dynorphin A was significantly decreased compared with in healthy controls. ${ }^{59}$ Therefore, a $\kappa$-opioid system in the psoriatic epidermis plays some role in the regulation of itching. According to these facts, nalfurafine can be effective in treating pruritus in psoriasis.

The injection of ethynylestradiol for 2 weeks reportedly induced cholestasis, and subsequently increased serum concentrations of bile acids and caused a higher incidence of body scratching compared with vehicle in rats, providing an animal model for scratching behavior secondary to cholestasis. Pretreating the rats with nalfurafine inhibited ethynylestradiol-induced scratching. Therefore, nalfurafine has the potential to reduce cholestatic pruritus. ${ }^{60}$ The aged MRL/lpr mice, a model of autoimmune disease, showed spontaneous scratching behavior. The frequency of this scratching behavior was not reduced by oral administration of an antihistamine chlorpheniramine, suggesting the behavior is antihistamine-resistant. In contrast, the oral administration of nalfurafine inhibited the scratching behavior without causing gross behavioral changes, suggesting nalfurafine may be beneficial in patients with autoimmune disease-associated pruritus. ${ }^{61}$

Chloroquine, a chemotherapeutic drug for malaria fever, can cause generalized pruritus. ${ }^{62,63}$ Experimentally, scratching behavior was induced by chloroquine in mice. However, when the mice were pretreated with nalfurafine, scratching was strongly suppressed ${ }^{64}$ Therefore, nalfurafine also is hopeful as a treatment for pruritus induced by drugs, including chloroquine.

In addition to the antipruritic activity, the analgesic effect of nalfurafine was examined using mice inoculated with herpes simplex virus I, and pain-related responses of the hind paw were monitored with von Frey filaments. ${ }^{65}$ Then it was found that oral nalfurafine suppressed herpetic and postherpetic pain dose-dependently. Thus, nalfurafine is also hopeful for antiherpetic and postherpetic neuralgia.

\section{Conclusion and perspective}

The newly approved oral drug nalfurafine hydrochloride ( 2.5 and $5 \mu \mathrm{g} / \mathrm{day}$ ), a $\kappa$-opioid receptor agonist, has been proven to be safe and effective for the treatment of HD patients with uremic pruritus resistant to antihistamines. This drug suppresses itching and subsequently improves the mental condition of HD patients. Nalfurafine can be recommended as a hopeful option for pruritus in HD patients when conventional treatments are not effective. Because $\kappa$-opioid receptors are expressed in the epidermis, topical nalfurafine may be developed for the treatment of pruritus associated with renal failure, hepatic diseases, and other pruritic skin diseases in the future. Because skin eruptions were not assessed in a previous clinical trial, ${ }^{16}$ it should be interesting to investigate the effect of nalfurafine on excoriations, lichen simplex, prurigo nodularis, and acquired perforating dermatosis possibly caused by uremic pruritus. From recent data showing $\kappa$-opioid receptor expression in 
the epidermis of atopic dermatitis and psoriasis, nalfurafine hydrochloride will be potentially used for these two skin diseases. In addition, various animal experiments suggest this drug will be helpful as an antipruritic drug for a wide range of skin diseases. In the future, clinical study is expected to be planned for various recalcitrant types of pruritus other than uremic pruritus.

As a new antipruritic for uremic pruritus, gabapentin and pregabalin were reported to show a high efficacy ratio $(81 \%) .{ }^{66}$ Moreover, pregabalin has been recently examined in a randomized double-blind study and found to reduce VAS for pruritus by $66 \mathrm{~mm}$ at 12 weeks after starting the drug. ${ }^{67}$ This reduction is remarkably larger than that by nalfurafine (41.6 $\mathrm{mm}$ at week 24 and $44 \mathrm{~mm}$ at week 52). Therefore, more new reagents for uremic pruritus can be expected to be developed in the near future.

\section{Disclosure}

The author reports no conflicts of interest in this work.

\section{References}

1. Nakai S, Hanafusa N, Masakane I, et al. An overview of regular dialysis treatment in Japan (as of December 31, 2012). Ther Apher Dial. 2014;18(6):535-602.

2. Pisoni RL, Wikström B, Elder SJ, et al. Pruritus in haemodialysis patients: International results from the Dialysis Outcomes and Practice Patterns Study (DOPPS). Nephrol Dial Transplant. 2006;21(12):3495-3505.

3. Narita I, Alchi B, Omori K, et al. Etiology and prognostic significance of severe uremic pruritus in chronic hemodialysis patients. Kidney Int. 2006;69(9):1626-1632.

4. Gunal AI, Ozalp G, Yoldas TK, Gunal SY, Kirciman E, Celiker H. Gabapentin therapy for pruritus in haemodialysis patients: a randomized, placebo-controlled, double-blind trial. Nephrol Dial Transplant. 2004;19(12):3137-3139.

5. Breneman DL, Cardone JS, Blumsack RF, Lather RM, Searle EA, Pollack VE. Topical capsaicin for treatment of hemodialysis-related pruritus. J Am Acad Dermatol. 1992;26(1):91-94.

6. Tarng DC, Cho YL, Liu HN, Huang TP. Hemodialysis-related pruritus: a double-blind, placebo-controlled, crossover study of capsaicin $0.025 \%$ cream. Nephron. 1996;72(4):617-622.

7. Gilchrest BA, Rowe JW, Brown RS, Steinman TI, Arndt KA. Ultraviolet phototherapy of uremic pruritus. Long-term results and possible mechanism of action. Ann Intern Med. 1979;91(1):17-21.

8. Silva SR, Viana PC, Lugon NV, Hoette M, Ruzany F, Lugon JR. Thalidomide for the treatment of uremic pruritus: a crossover randomized double-blind trial. Nephron. 1994;67(3):270-273.

9. Szepietowski JC, Szepietowski T, Reich A. Efficacy and tolerance of the cream containing structured physiological lipids with endocannabinoids in the treatment of uremic pruritus: a preliminary study. Acta Dermatovenerol Croat. 2005;13(2):97-103.

10. Pauli-Magnus C, Klumpp S, Alscher DM, Kuhlmann U, Mettang T. Short-term efficacy of tacrolimus ointment in severe uremic pruritus. Perit Dial Int. 2000;20(6):802-803.

11. Kuypers DR, Claes K, Evenepoel P, Maes B, Vanrenterghem Y. A prospective proof of concept study of the efficacy of tacrolimus ointment on uraemic pruritus (UP) in patients on chronic dialysis therapy. Nephrol Dial Transplant. 2004;19(7):1895-1901.

12. Balaskas EV, Uldall RP. Erythropoietin treatment does not improve uremic pruritus. Perit Dial Int. 1992;12(3):330-331.
13. De Marchi S, Cecchin E, Villalta D, Sepiacci G, Santini G, Bartoli E. Relief of pruritus and decreases in plasma histamine concentrations during erythropoietin therapy in patients with uremia. $N$ Engl J Med. 1992;326(15):969-974.

14. Peer G, Kivity S, Agami O, et al. Randomised crossover trial of naltrexone in uraemic pruritus. Lancet. 1996;348(9041):1552-1554.

15. Pauli-Magnus C, Mikus G, Alscher DM, et al. Naltrexone does not relieve uremic pruritus: results of a randomized, double-blind, placebocontrolled crossover study. J Am Soc Nephrol. 2000;11(3):514-519.

16. Kumagai H, Ebata T, Takamori K, Muramatsu T, Nakamoto H, Suzuki H. Effect of a novel kappa-receptor agonist, nalfurafine hydrochloride, on severe itch in 337 haemodialysis patients: a Phase III, randomized, double-blind, placebo-controlled study. Nephrol Dial Transplant. 2010; 25(4):1251-1257.

17. Abdelbaqi-Salhab M, Shalhub S, Morgan MB. A current review of the cutaneous manifestations of renal disease. J Cutan Pathol. 2003;30(9): 527-538.

18. Mettang T, Kremer AE. Uremic pruritus. Kidney Int. Epub January 8 , 2014.

19. Mathur VS, Lindberg J, Germain M, et al; ITCH National Registry Investigators. A longitudinal study of uremic pruritus in hemodialysis patients. Clin J Am Soc Nephrol. 2010;5(8):1410-1419.

20. Kleeman CR, Massry SG, Popovtzer MM, Makoff DL, Maxwell MH, Coburn JW. The disappearance of intractable pruritus after parathyroidectomy in uremic patients with secondary hyperparathyroidism. Trans Assoc Am Physicians. 1968;81:203-212.

21. Massry SG, Popovtzer MM, Coburn JW, Makoff DL, Maxwell MH, Kleeman CR. Intractable pruritus as a manifestation of secondary hyperparathyroidism in uremia. Disappearance of itching after subtotal parathyroidectomy. N Engl J Med. 1968;279(13):697-700.

22. Ståhle-Bäckdahl M, Hägermark $\mathrm{O}$, Lins LE, Törring $\mathrm{O}$, Hilliges $M$, Johansson O. Experimental and immunohistochemical studies on the possible role of parathyroid hormone in uraemic pruritus. J Intern Med. 1989;225(6):411-415.

23. Mettang T, Fritz P, Weber J, Machleidt C, Hübel E, Kuhlmann U. Uremic pruritus in patients on hemodialysis or continuous ambulatory peritoneal dialysis (CAPD). The role of plasma histamine and skin mast cells. Clin Nephrol. 1990;34(3):136-141.

24. Stockenhuber F, Kurz RW, Sertl K, Grimm G, Balcke P. Increased plasma histamine levels in uraemic pruritus. Clin Sci (Lond). 1990; 79(5):477-482.

25. Weisshaar E, Dunker N, Röhl FW, Gollnick H. Antipruritic effects of two different 5-HT3 receptor antagonists and an antihistamine in haemodialysis patients. Exp Dermatol. 2004;13(5):298-304.

26. Dugas-Breit S, Schöpf P, Dugas M, Schiffl H, Ruëff F, Przybilla B. Baseline serum levels of mast cell tryptase are raised in hemodialysis patients and associated with severity of pruritus. J Dtsch Dermatol Ges. 2005;3(5):343-347.

27. Masmoudi A, Hajjaji Darouiche M, Ben Salah H, Ben Hmida M, Turki H. Cutaneous abnormalities in patients with end stage renal failure on chronic hemodialysis. A study of 458 patients. J Dermatol Case Rep. 2014;8(4):86-94.

28. Koulentaki M, Ioannidou D, Stefanidou M, et al. Dermatological manifestations in primary biliary cirrhosis patients: a case control study. $\mathrm{Am}$ J Gastroenterol. 2006;101(3):541-546.

29. Tominaga M, Ozawa S, Tengara S, Ogawa H, Takamori K. Intraepidermal nerve fibers increase in dry skin of acetone-treated mice. J Dermatol Sci. 2007;48(2):103-111.

30. Johansson O, Hilliges M, Ståhle-Bäckdahl M. Intraepidermal neuronspecific enolase (NSE)-immunoreactive nerve fibres: evidence for sprouting in uremic patients on maintenance hemodialysis. Neurosci Lett. 1989;99(3):281-286.

31. Kuraishi Y, Yamaguchi T, Miyamoto T. Itch-scratch responses induced by opioids through central mu opioid receptors in mice. J Biomed Sci. 2000;7(3):248-252.

32. Kardon AP, Polgár E, Hachisuka J, et al. Dynorphin acts as a neuromodulator to inhibit itch in the dorsal horn of the spinal cord. Neuron. 2014;82(3):573-586. 
33. Szmuszkovicz J, Von Voigtlander PF. Benzeneacetamide amines: structurally novel non-m mu opioids. J Med Chem. 1982;25(10): $1125-1126$.

34. Millan MJ. Kappa-opioid receptors and analgesia. Trends Pharmacol Sci. 1990;11(2):70-76.

35. Nagase H, Hayakawa J, Kawamura K, et al. Discovery of a structurally novel opioid kappa-agonist derived from 4,5-epoxymorphinan. Chem Pharm Bull (Tokyo). 1998;46(2):366-369.

36. Portoghese AS, Lipkowski AW, Takemori AE. Bimorphinans as highly selective, potent kappa opioid receptor antagonists. J Med Chem. 1987;30(2):238-239.

37. Portoghese PS, Nagase H, Lipkowski AW, Larson DL, Takemori AE. Binaltorphimine-related bivalent ligands and their kappa opioid receptor antagonist selectivity. J Med Chem. 1988;31(4):836-841.

38. Seki T, Awamura S, Kimura C, et al. Pharmacological properties of TRK-820 on cloned mu-, delta- and kappa-opioid receptors and nociceptin receptor. Eur J Pharmacol. 1999;376(1-2):159-167.

39. Nakao K, Ikeda K, Kurokawa T, et al. [Effect of TRK-820, a selective kappa opioid receptor agonist, on scratching behavior in an animal model of atopic dermatitis]. Nihon Shinkei Seishin Yakurigaku Zasshi. 2008;28(2):75-83. Japanese.

40. Nakao K, Mochizuki H. Nalfurafine hydrochloride: a new drug for the treatment of uremic pruritus in hemodialysis patients. Drugs Today (Barc). 2009;45(5):323-329.

41. Togashi Y, Umeuchi H, Okano K, et al. Antipruritic activity of the kappa-opioid receptor agonist, TRK-820. Eur J Pharmacol. 2002; 435(2-3):259-264.

42. Umeuchi $\mathrm{H}$, Togashi $\mathrm{Y}$, Honda $\mathrm{T}$, et al. Involvement of central mu-opioid system in the scratching behavior in mice, and the suppression of it by the activation of kappa-opioid system. Eur J Pharmacol. 2003;477(1):29-35.

43. Mori T, Nomura M, Nagase H, Narita M, Suzuki T. Effects of a newly synthesized kappa-opioid receptor agonist, TRK-820, on the discriminative stimulus and rewarding effects of cocaine in rats. Psychopharmacology (Berl). 2002;161(1):17-22.

44. Wikström B, Gellert R, Ladefoged SD, et al. Kappa-opioid system in uremic pruritus: multicenter, randomized, double-blind, placebocontrolled clinical studies. J Am Soc Nephrol. 2005;16(12):3742-3747.

45. Kumagai H, Ebata T, Takamori K, et al. Efficacy and safety of a novel $\kappa$-agonist for managing intractable pruritus in dialysis patients. Am J Nephrol. 2012;36(2):175-183.

46. Ueno Y, Mori A, Yanagita T. One year long-term study on abuse liability of nalfurafine in hemodialysis patients. Int J Clin Pharmacol Ther. 2013;51(11):823-831.

47. Araujo SM, de Bruin VM, Daher EF, Almeida GH, Medeiros CA, de Bruin PF. Risk factors for depressive symptoms in a large population on chronic hemodialysis. Int Urol Nephrol. 2012;44(4):1229-1235.

48. Inui S, Shirakawa Y, Itami S. Effect of nalfurafine hydrochloride on pruritus and anxiety level in hemodialysis patients. $J$ Dermatol. 2012;39(10):886-887.

49. Oh SH, Bae BG, Park CO, et al. Association of stress with symptoms of atopic dermatitis. Acta Derm Venereol. 2010;90(6):582-588.

50. Globe D, Bayliss MS, Harrison DJ. The impact of itch symptoms in psoriasis: results from physician interviews and patient focus groups. Health Qual Life Outcomes. 2009;7(1):62.

51. Willebrand M, Low A, Dyster-Aas J, et al. Pruritus, personality traits and coping in long-term follow-up of burn-injured patients. Acta Derm Venereol. 2004;84(5):375-380.
52. Nakazato K, Shimonaka Y. The Japanese State-Trait Anxiety Inventory: age and sex differences. Percept Mot Skills. 1989;69(2):611-617.

53. Tominaga $\mathrm{M}$, Ogawa $\mathrm{H}$, Takamori K. Possible roles of epidermal opioid systems in pruritus of atopic dermatitis. J Invest Dermatol. 2007;127(9):2228-2235.

54. Nakasone T, Sato T, Matsushima Y, Inoue T, Kamei C. Characteristics of scratching behavior in ADJM mice (atopic dermatitis from Japanese mice). Immunopharmacol Immunotoxicol. Epub January 12, 2015.

55. Stinco G, Trevisan G, Piccirillo F, et al. Pruritus in chronic plaque psoriasis: a questionnaire-based study of 230 Italian patients. Acta Dermatovenerol Croat. 2014;22(2):122-128.

56. Mrowietz U, Chouela EN, Mallbris L, et al. Pruritus and quality of life in moderate-to-severe plaque psoriasis: post hoc explorative analysis from the PRISTINE study. J Eur Acad Dermatol Venereol. Epub November 5, 2014.

57. Altunay IK, Atis G, Esen K, Kucukunal A. Impact of functional pruritus compared with mild psoriasis on quality of life: a cross-sectional questionnaire study in Turkey. Am J Clin Dermatol. 2014;15(4):365-370.

58. Yosipovitch G, Goon A, Wee J, Chan YH, Goh CL. The prevalence and clinical characteristics of pruritus among patients with extensive psoriasis. Br J Dermatol. 2000;143(5):969-973.

59. Taneda K, Tominaga M, Negi O, et al. Evaluation of epidermal nerve density and opioid receptor levels in psoriatic itch. $\mathrm{Br} J$ Dermatol. 2011;165(2):277-284

60. Inan S, Cowan A. Nalfurafine, a kappa opioid receptor agonist, inhibits scratching behavior secondary to cholestasis induced by chronic ethynylestradiol injections in rats. Pharmacol Biochem Behav. 2006;85(1): 39-43.

61. Umeuchi H, Kawashima Y, Aoki CA, et al. Spontaneous scratching behavior in MRL/lpr mice, a possible model for pruritus in autoimmune diseases, and antipruritic activity of a novel kappa-opioid receptor agonist nalfurafine hydrochloride. Eur J Pharmacol. 2005;518(2-3): 133-139.

62. Olatunde A. The practical and therapeutic implications of chloroquineinduced itching in tropical Africa. Afr J Med Med Sci. 1977;6(1): 27-32.

63. Spencer HC, Poulter NR, Lury JD, Poulter CJ. Chloroquine-associated pruritus in a European. Br Med J (Clin Res Ed). 1982;285(6356): 1703-1704.

64. Inan S, Cowan A. Kappa opioid agonists suppress chloroquine-induced scratching in mice. Eur J Pharmacol. 2004;502(3):233-237.

65. Takasaki I, Nojima H, Shiraki K, Kuraishi Y. Specific down-regulation of spinal mu-opioid receptor and reduced analgesic effects of morphine in mice with postherpetic pain. Eur J Pharmacol. 2006;550(1-3): 62-67.

66. Rayner H, Baharani J, Smith S, Suresh V, Dasgupta I. Uraemic pruritus: relief of itching by gabapentin and pregabalin. Nephron Clin Pract. 2012;122(3-4):75-79.

67. Yue J, Jiao S, Xiao Y, Ren W, Zhao T, Meng J. Comparison of pregabalin with ondansetron in treatment of uraemic pruritus in dialysis patients: a prospective, randomized, double-blind study. Int Urol Nephrol. 2015; 47(1):161-167.
Clinical, Cosmetic and Investigational Dermatology

\section{Publish your work in this journal}

Clinical, Cosmetic and Investigational Dermatology is an international, peer-reviewed, open access, online journal that focuses on the latest clinical and experimental research in all aspects of skin disease and cosmetic interventions. All areas of dermatology wil be covered; contributions will be welcomed from all clinicians and

\section{Dovepress}

basic science researchers globally. This journal is indexed on CAS The manuscript management system is completely online and includes a very quick and fair peer-review system, which is all easy to use. Visit http://www.dovepress.com/testimonials.php to read real quotes from published authors. 